\title{
Antigas narrativas, contemporânea crise: raízes e disputas das três correntes discursivas ambientalistas
}

\author{
Mariana Freitas Alvim' \\ https://orcid.org/0000-0002-0165-2962 \\ I - Pontifícia Universidade Católica de São Paulo. \\ São Paulo (SP), Brasil.
}

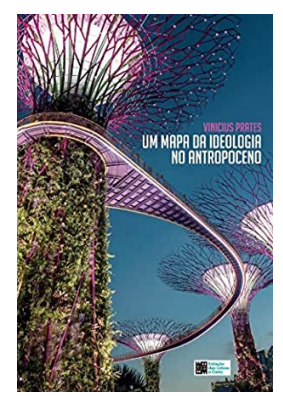

PRATES, V.

Um mapa da ideologia no antropoceno.

Barueri: Estação das Letras e Cores,

2020. 186p.

Resumo: O robusto trabalho de análise discursiva demonstrado por Vinicius Prates no livro Um mapa da ideologia no antropoceno é apresentado nesta resenha, com ênfase na abordagem da Escola de Essex, acionada pelo autor, que categoriza e detalha três correntes discursivas do ambientalismo: o ecologismo profundo, o ecologismo reformista e o ecologismo radical. Prates recorre a grandes narrativas anteriores à crise ambiental para mostrar as raízes dessas correntes, analisando também seus modos de agir e falar na contemporaneidade - evidenciando que elas formam uma batalha discursiva ainda em aberto. 
Palavras-chave: discurso; meio ambiente; ambientalismo; ecologismo; ideologia.

\begin{abstract}
Old narratives, contemporary crisis: the roots and battles of three discursive currents in the environmental field - The robust work of discursive analysis demonstrated by Vinicius Prates in the book Um mapa da ideologia no antropoceno is presented in this review, with an emphasis on the approach of the Essex School followed by the author, who categorizes and details three discursive currents of environmentalism: the deep ecology, the reformist ecology and the radical ecology. Prates goes back to great narratives prior to the environmental crisis in order to show the roots of these currents; and also analyses their ways of acting and speaking out in contemporaneity - showing that they make up a discursive battle that is still unsolved.
\end{abstract}

Keywords: discourse; environment; environmentalism; ecology; ideology.

As três correntes discursivas do ambientalismo, apresentadas por Vinicius Prates em Um Mapa da Ideologia no Antropoceno, têm raízes históricas, interpretações e propostas marcadamente distintas, mas guardam em comum o reconhecimento da enorme crise ambiental fustigada e enfrentada, hoje e pelas próximas décadas, pelos humanos. Sendo, então, esta crise tão inequívoca, grave e urgente, são mais do que bem-vindos - e necessários estudos pioneiros e qualificados sobre o tema nas ciências humanas, como o apresentado por Prates no livro.

Cada uma recebendo um capítulo próprio de explanação, as três correntes trabalhadas por Prates remetem a uma divisão triádica proposta por outros autores, sobretudo Marc Guillaume, que fala em ecologismo profundo, reformista e radical. É preciso apontar, porém, que essa referência a outras obras poderia ter sido explicitada anteriormente e com mais frequência no livro. A conexão com o trabalho de outros autores ganha basicamente uma menção no final do primeiro capítulo, faltando uma apresentação mais completa das obras e das justificativas para a sua escolha.

Essa lacuna, porém, se torna menor conforme o apurado trabalho é apresentado. Ao relacionar as três correntes do ambientalismo com grandes narrativas, até anteriores à crise ambiental, e que ultrapassam o tema ecológico, o autor oferece uma leitura enriquecedora para acompanharmos não só as próximas décadas consequentes do Antropoceno (era geológica em que a influência humana no planeta é considerada), mas também para a compreensão de conceitos e teorias fundamentais nas ciências sociais, como o discurso mítico-religioso, os fundamentos ideológicos do liberalismo e a crítica a este modelo socioeconômico. 
[...] o ecologismo profundo é um caso específico do discurso mítico-religioso, que busca dotar o 'meio ambiente' dos sentidos de sacralidade, agregando-Ihe prioritariamente significantes como 'natureza intocada', 'pureza', 'beleza' etc., para aproximá-lo de sua rede de equivalências simbólicas; o ecologismo reformista busca conjuminar numa relação harmoniosa os sentidos do meio ambiente em crise e os objetos de valor do liberal-capitalismo, como 'modernidade', 'competência', 'tecnologia' etc.; o ecologismo radical, por sua vez, se estabelece numa cadeia de significantes que busca transformar o meio ambiente num equivalente das tradicionais palavras de ordem da esquerda política, como 'revolução', 'justiça social', 'igualdade' etc. (PRATES, 2020, p.41)

Ao recorrer a palavras como equivalências simbólicas, sentidos e significantes, o autor explicita a abordagem teórico-epistemológica com que trabalha: a do discurso como campo de disputa, e disputa ideológica. No primeiro capítulo, Prates apresenta autores clássicos que são base para essa leitura, como Ferdinand de Saussure, Dominique Maingueneau, Louis Althusser, Mikhail Bakhtin, Michel Foucault, Michel Pêcheux e Volóchinov, para depois detalhar a Escola de Essex, sua principal referência teórica, e que tem como representantes Ernesto Laclau, Chantal Mouffe, Yannis Stavrakakis, David Howarth, Jacob Torfing, entre outros. Essa escola, segundo explanação de Prates, tem vários pontos em comum com a análise de discurso francesa, mas ressalta particularmente o pensamento político de Antonio Gramsci e o psicanalítico de Jacques Lacan.

Segundo Laclau (2013), o discurso é tudo aquilo que existe, uma vez que é formado um complexo relacional, não se restringindo, portanto, à fala ou à escrita. A linguagem é inerentemente constituída por diferenças, então a "totalização hegemônica" é justamente um "investimento radical", por associar significados diferentes em uma cadeia relacional, que é sempre incompleta (LACLAU, 2013, p.120). Acompanhando a psicanálise, este autor vai dizer que as identidades, os discursos e o social são sempre parciais, pois são constituídos "no ponto de encontro da diferença e da equivalência" (ibidem, p. 133). A hegemonização, inclusive na política, é orientada pela sutura dos antagonismos em direção à totalização, mas ela é sempre limitada pela negatividade inerente às relações. Assim, uma espécie de ciclo disputashegemonização vai se repetindo.

Uma vez que o ambientalismo não é um discurso acabado, correntes antagonistas estão buscando estabelecer suas cadeias de equivalência a partir 
de um significante, ou ponto nodal, que articula os elementos do discurso: o meio ambiente. Apesar dessa disputa ainda estar em curso, as correntes recorrem aos discursos há muito tempo estabilizados: “[...] cada corrente do ecologismo se comporta como um caso específico e aplicado de uma dessas grandes narrativas [...]" (PRATES, 2020, p.42).

Após um primeiro capítulo em que o Antropoceno e as bases teóricoepistemológicas do trabalho são apresentados, o segundo capítulo se dedica à corrente do ecologismo profundo. Esta recorre às narrativas do sagrado, como a preponderância dos ciclos e a valorização dos anciões como detentores do saber. Há também um argumento estético nessa corrente: a natureza guarda uma beleza que pode ser explorada pelos humanos apenas em uma relação de admiração e estesia. Nada além disso. É seguro, e mesmo ético, manter a humanidade e a natureza separadas, o que explica a identificação do ecologismo profundo com a luta pela proteção de espaços intocados e da biodiversidade.

Embora esses ecologistas não necessariamente sigam uma tradição religiosa ou filosófica específica, a divisão entre natureza e cultura lembra aquilo que, segundo o filósofo italiano Giorgio Agamben, é o fundamento de toda religião: a separação. Prates relaciona também o ecologismo profundo ao Romantismo na Europa dos séculos XVIII e XIX, movimento filosófico e artístico que ganha uma generosa e embasada apresentação no capítulo 2. A reação dos românticos aos exageros intelectualistas do lluminismo e da ciência é também conectada por Prates à contracultura, ao movimento hippie dos anos 1960-1970 e ao modelo de vida das ecovilas.

O capítulo 3 explora o ecologismo reformista, um discurso do próprio liberal-capitalismo sobre a crise ambiental nascida em seu cerne. E as soluções propostas também vêm daí: a corrente defende a compatibilidade entre preservação ambiental e desenvolvimento econômico, em que a aparente contradição seria conciliada pela tecnologia.

O autor traz consigo, nesse capítulo, a bagagem de uma longa pesquisa que vem desempenhando sobre a produção midiática acerca da crise ambiental. A mídia é, inclusive, um dos principais representantes do discurso do ecologismo reformista, junto com organismos transnacionais como a ONU, acionistas e empresários, que vocalizam o compromisso com o "desenvolvimento sustentável", um dos termos associados à corrente. Em um artigo baseado em sua tese, Prates (2017) lembra que o tema 
ambiental está nas campanhas publicitárias - até mesmo de empresas petrolíferas, responsáveis por grandiosas emissões de poluentes -, em relatórios de sustentabilidade das empresas, na imprensa, entre outros. Não seria diferente com o jornalismo especializado em economia e negócios, que tem a peculiaridade de precisar lidar com a tensão entre o discurso do liberal-capitalismo, base de seu contrato de comunicação, e a publicação de conteúdo sobre a degradação ambiental provocada por esse sistema, imposta pelo noticiário.

A partir da análise da produção das revistas mais influentes desse segmento no Brasil - Exame, Época Negócios e IstoÉ Dinheiro -, o autor demonstra que parte do conteúdo apresenta a "onda" ecológica como nova possibilidade de ganho - de lucro, de novos mercados, de uma boa imagem para as empresas, entre outros. Mas outra parte importante da produção midiática aposta na conciliação do mercado com o meio ambiente, e a tecnologia tem papel fundamental nisso: "Os enunciados da imprensa corporativa mencionam obsessivamente a tecnologia como solução para a crise ambiental" (PRATES, 2020, p. 104). Ou seja, a ciência e a técnica denunciadas pelo ecologismo profundo por seus excessos, são escaladas como solução para a crise ambiental pelos reformistas.

Segundo explica Prates, o discurso reformista está mais próximo do liberalismo clássico dos séculos XVIII e XIX, do que o "capitalismo selvagem" representado pelo neoliberalismo. Assim, o autor do livro procura as bases dessa corrente do ambientalismo em fundadores do liberalismo como John Locke (1632-1704), ou mesmo em teóricos contemporâneos como John Rawls, que tentam entrelaçar os direitos à vida, à liberdade e à propriedade. Como jusnaturalista, Locke, assim como Jean-Jacques Rousseau e Thomas Hobbes, representou um esforço pioneiro em fundamentar o direito em causas puramente humanas - abandonando todo o determinismo religioso que estruturava a sociedade da época e os privilégios da nobreza. Os utilitaristas Jeremy Bentham (1748-1832) e John Stuart Mill (1806-1873), por sua vez, delinearam uma ética normativa segundo a qual, nas palavras de Prates e em linhas gerais, "a melhor ação é a que acarreta a maior felicidade para o maior número de indivíduos [...]" (ibidem, p. 95). Portanto, em resumo, o homem exploraria uma racionalidade inerente que permitiria a fruição dos direitos ao bem-estar e à liberdade, um pilar ético que baseia hoje o enfrentamento à crise ambiental na perspectiva do ecologismo reformista.

A crítica ao capitalismo mais embasada teoricamente e orientada politicamente vem não do ecologismo profundo, mas do ecologismo radical, que tem 
raízes no marxismo e é explorado por Vinicius Prates no capítulo 4. A natureza não é mais apartada do homem, e sim colocada como objeto e vítima desse sistema de produção, consumo e vivência. Falamos no modo de vida moldado pelo capitalismo, pois Prates dedica algumas páginas à chamada esquerda lacaniana, que estuda justamente a produção e a distribuição do gozo no capitalismo, mobilizadas pelo consumo. Ressalva-se que essa é a corrente cuja apresentação mais se confunde com a fundamentação teórica, que em alguns momentos deixa a dúvida se está servindo mais à construção de sua origem discursiva ou à própria justificativa de pesquisa do autor.

Para os ecologistas radicais, o representante material e simbólico do capitalismo, o dinheiro, divide aqueles que usufruirão da natureza e aqueles que sofrerão com sua degradação. Portanto, em defesa do meio ambiente e da própria humanidade, essa corrente quer uma mudança radical desse sistema - e, discursivamente, por ser um problema generalizado, o significante crise ambiental seria capaz de aglutinar outras demandas democráticas. Prates define o ecologismo radical como uma "espécie de galáxia à esquerda do espectro político, dispersa em elementos flutuantes desprendidos da antiga cadeia de significantes do marxismo clássico" (ibidem, p.124).

Dispersão e heterogeneidade de demandas são características do ecologismo radical, criticadas por teóricos como Bruno Latour e, em certa medida, pelo próprio autor de Um Mapa da Ideologia no Antropoceno. A fragmentação é, aliás, um problema da política na pós-modernidade, segundo Prates, em que movimentos e organizações diversas com alguns objetivos em comum, surgidos no final da década de 1970 - ambientalistas, ativistas pela diversidade de gênero, aqueles que lutam por melhorias a níveis locais etc. - , têm dificuldades de articulação: “[...] a ausência de um ponto nodal unificador no pós-moderno faz com que a micropolítica seja o nome de uma 'política possível', que abandonou qualquer pretensão de um discurso que represente a 'sutura última' da sociedade [...]" (ibidem, p. 125).

Na conclusão do livro, o autor reconhece que a categorização é sempre limitada e incapaz de abarcar todas as complexidades e nuances além do discurso - neste caso, o teórico. É inegável, porém, que a divisão triádica das correntes do ambientalismo é ricamente embasada e didaticamente exposta no livro, dando ao leitor um farto material para discussões contemporâneas acerca do meio ambiente e revisões bibliográficas igualmente enriquecedoras sobre as grandes narrativas da modernidade e teorias do discurso. Mencionado nas últimas duas páginas de Um Mapa da Ideologia 
no Antropoceno, o negacionismo climático e sua recusa ao reconhecimento do papel humano nas mudanças climáticas deixam o convite para um fascinante trabalho sobre esse discurso, cujo estudo é urgente por sua projeção na política e por seu potencial destruidor.

Mariana Freitas Alvim é jornalista, doutoranda no Programa de Estudos Pós-graduados em Comunicação e Semiótica da PUC-SP e mestre em sociologia pela UFRJ.

alvim.mariana@gmail.com

\section{Referências}

LACLAU, E. A razão populista. Tradução de Carlos Eugênio Marcondes de Moura. São Paulo: Três Estrelas, 2013.

PRATES, V. Da natureza deslocada à fantasia sustentável. In: PRADO, J. L. A.; PRATES, V. (orgs.). Sintoma e fantasia no capitalismo comunicacional. São Paulo: Estação das Letras e Cores, 2017.

PRATES, V. Um mapa da ideologia no antropoceno. Barueri: Estação das Letras e Cores, 2020.

Resenha recebida em 10/06/2021 e aprovada em 05/07/2021. 